\title{
Identification of Defects and Hazards in Structures Based on the Point Cloud Using the OptD Method
}

\author{
Joanna Janicka and Wioleta Błaszczak-Bąk
}

University of Warmia and Mazury in Olsztyn, Institute of Geodesy, ul. Oczapowskiego 1, 10-719

Olsztyn, Poland, joanna.janicka@uwm.edu.pl,wioleta.blaszczak@uwm.edu.pl

\begin{abstract}
Structural changes taking place in buildings and structures due to the passage of time are a normal phenomenon. However, the building objects are also adversely affected by atmospheric conditions or violent natural phenomena. Every year, our surroundings are increasingly attacked by extreme weather phenomena such as: floods, hurricanes, heavy storms with rain or extreme heat. Such phenomena are natural elements of nature, however they significantly interfere in the technical condition of the building. They often cause measurable economic losses: flooding, cracks, construction displacements and even their total destruction. At the time of estimating losses, calculating the costs of repair, and then making decisions about the method of restoration, a helpful tool can be laser scanning: terrestrial, airborne or mobile, depending on the character of the object and the size of the disaster. The paper presents an identification of defects and hazards in structures based on the point cloud using the OptD method.
\end{abstract}

Keywords: Buildings, TLS, OptD, Defects, Hazards.

\section{Introduction}

Building objects are subject of the influence of various factors that affect their technical condition. Every day various types of atmospheric conditions and weather phenomena occurs (wind, snow, rain, sun) but there are also such as violent phenomena that are usually extreme (hurricanes, floods, earthquakes, etc.). Either way, when the technical condition deteriorates, engineering objects should be monitoring periodically or due to the impact of a sudden phenomenon.

Traditional methods of checking the condition of buildings are extensively time consuming, laborious, and expensive and pose health and safety threats to surveyors. They rely on the employment of building inspectors, who assess the technical condition. Inspections take a long time because they require many photos, drawings and notes. It sometimes happens that inspector has to return to the inspection site many times because not all relevant information has been registered. Therefore, further suggestions are being made to solve this problem, such as the use of wireless sensor networks or smartphone sensors (Noel A.B. et al.,2017), (Kong Q. et al., 2018). In addition, classic inventory may pose a threat to building inspectors, especially in hard to reach places or at heights (Perez H. Taha J.H.M and Mosavi A. 2019). Another factor that is important is the timing of inventory taking. In the manuscript authors (Perez H. Tahy J.H.M and Mosavi A. 2019) also noticed that clients are increasingly looking for fast and effective means to quickly and frequently survey and communicate the condition of their buildings. Therefore, the search for new ways to obtain a large amount of data in the shortest possible time is also a topic that appears in the area of conducting building monitoring. 
Terrestrial laser scanning has been widely used for many years, especially when creating various types of architectural documentation. It can be also used to monitor various types of objects for example: buildings (Przyborski and Tysiąc 2018), forests (Liang X. et al., 2016), power lines (Maikainen, L. et al., 2016) etc.

It allows to collect a large dataset saved as a three-dimensional coordinates and intensity parameter. Having access to this type of data, one can conduct various types of analyses, simulations, calculations, etc. About effective use of both terrestrial laser scanning and the OptD method used to identify various defects in buildings one can read in manuscripts (Suchocki and Blaszczak-Bak 2019), (Sochocki et al., 2019).

\section{OptD Method Description}

TLS measurement technology is relatively simple, fast and effective technique for obtaining data, which one can then develop according to your preferences. The biggest problem for the operator is the size of the datasets. Many times, these are multi GB files. Data can be recorded with different resolutions ranging from tens of centimeters to single millimeters. The resolution and range of the measurement has an impact on the time of measurement but also on the final results.

Thus, obtaining data is only part of the task associated with the use of point clouds to identify defects and hazards in building constructions. If the object is scanned with high resolution, the acquired point cloud is a huge data set. Usually its original size is difficult to process because it requires high performance hardware. The solution to this problem is to
reduce the point cloud by eliminating some points. Commercial programs usually contain basid
methods of data reduction: random or with an assumed interval, etc. The disadvantage of doing
so is that as a result of random reduction one can lose many valuable points associated with the
geometrical features of the object. The proposal presented in this paper is to use the otD method during data processing.

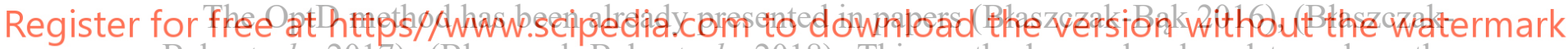
Bąk et al., 2017), (Błaszczak-Bąk et al., 2018). This method was developed to reduce the dataset without losing the information that is necessary for the correct implementation of the planned task. It allows to reduce the dataset significantly, but preserving the characteristics of the object, and in particular, to obtain points representing the study object. The OptD method is carried out in the following stages by Suchocki and Błaszczak-Bąk (2019).

The diagram showing the principle of operation of the OptD method that was used during the tests is shown in Figure 1.

\section{Description of Sample Objects}

As it was mentioned at the beginning, one can distinguish construction objects that should be inventoried because they are deteriorating due to the passage of time or those whose technical condition has deteriorated due to an event related to the operation of nature. Regardless of the reason of the inventory, it happens that staying inside the inventoried object can be dangerous for the inspector, or there are uncomfortable conditions for longer staying. It may also happens that direct access to the defect is difficult or not available. The paper present selected cases that were the subject of measurement and with which the authors have personally encountered. 


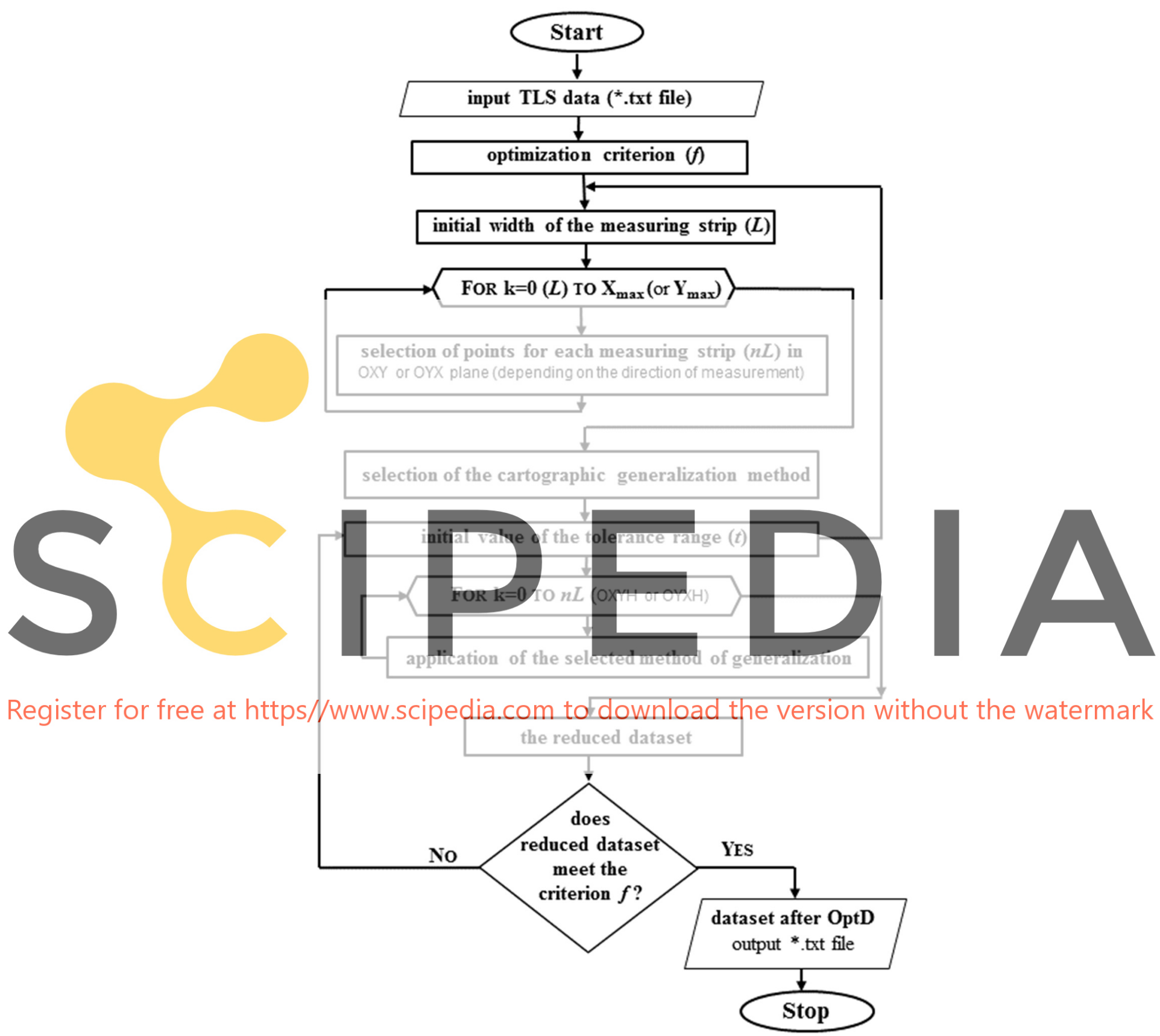

Figure 1. The scheme of the OptD reduction method.

Figure 2 presents the ruins of historic tower. In case of this tower's ruin important is to keep the fragments that are still in a quite good condition. Besides, in the underground of these 
buildings there are also basements with no access to daylight. Due to the fact that there is no access to daylight or even artificial light and that the above ground remains of the tower are in a very poor condition, being in its underground is very dangerous. The technical condition of the basement is periodically checked and in this case, a terrestrial laser scanner can be a great tool because it doesn't require access to light during measurements.

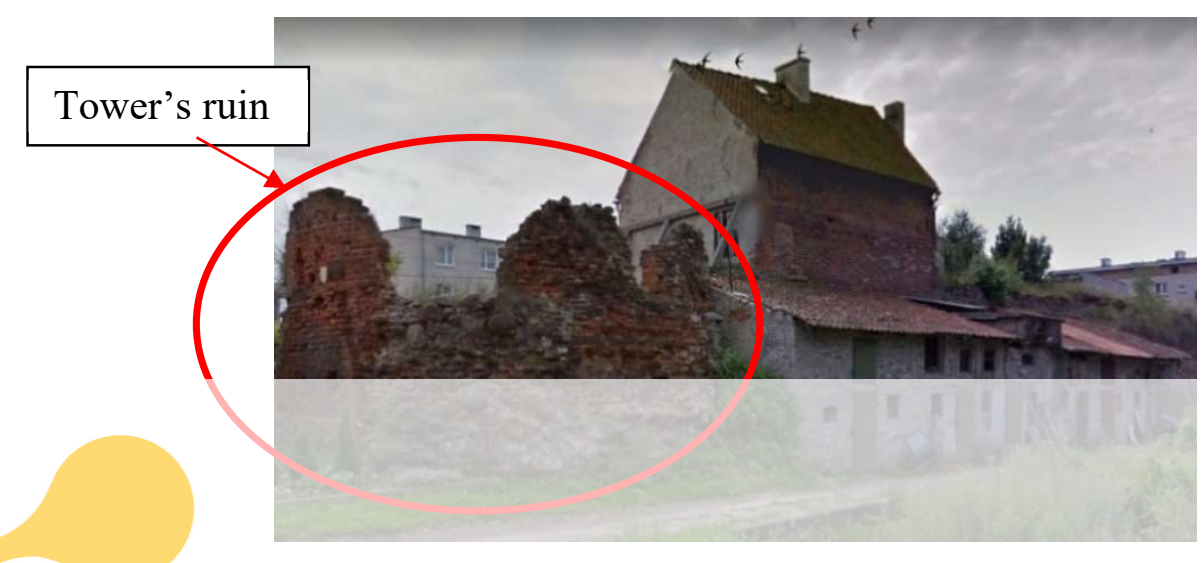

Figure 2. The ruins of historic tower.

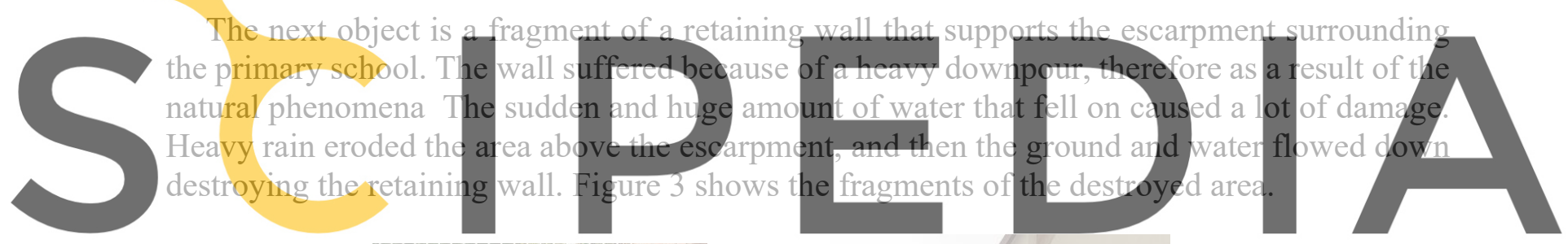

Register for free at https//www.scipedia.com to download the version without the watermark
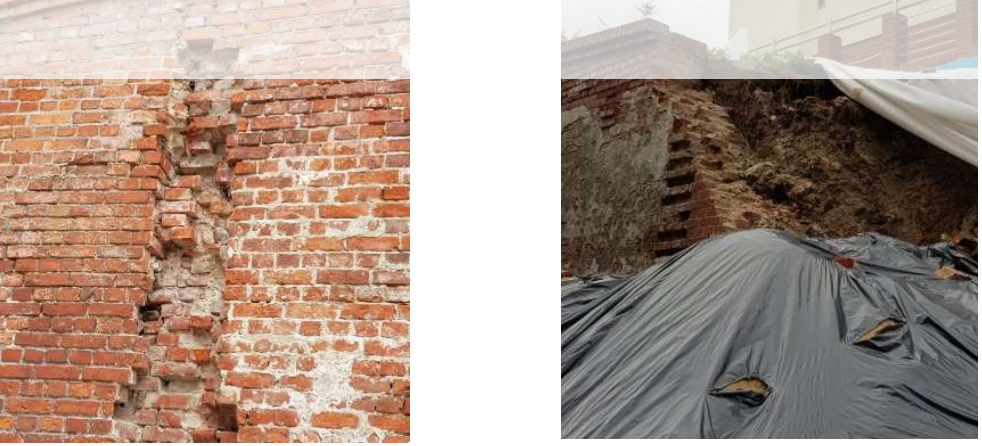

Figure 3. Retaining wall destroyed as a result of heavy rain.

The last example is an object exposed to deformation due to subsidence. This is a church and monastery of Franciscan fathers in Barczewo, that was built in the 14th century. The Gothic church needs urgent renovation because its technical condition has deteriorated significantly.

The main reason is age and the unstable ground on which the church was built. As a result one of the church walls tilted significantly and cracked what is presented in Figure 4. 


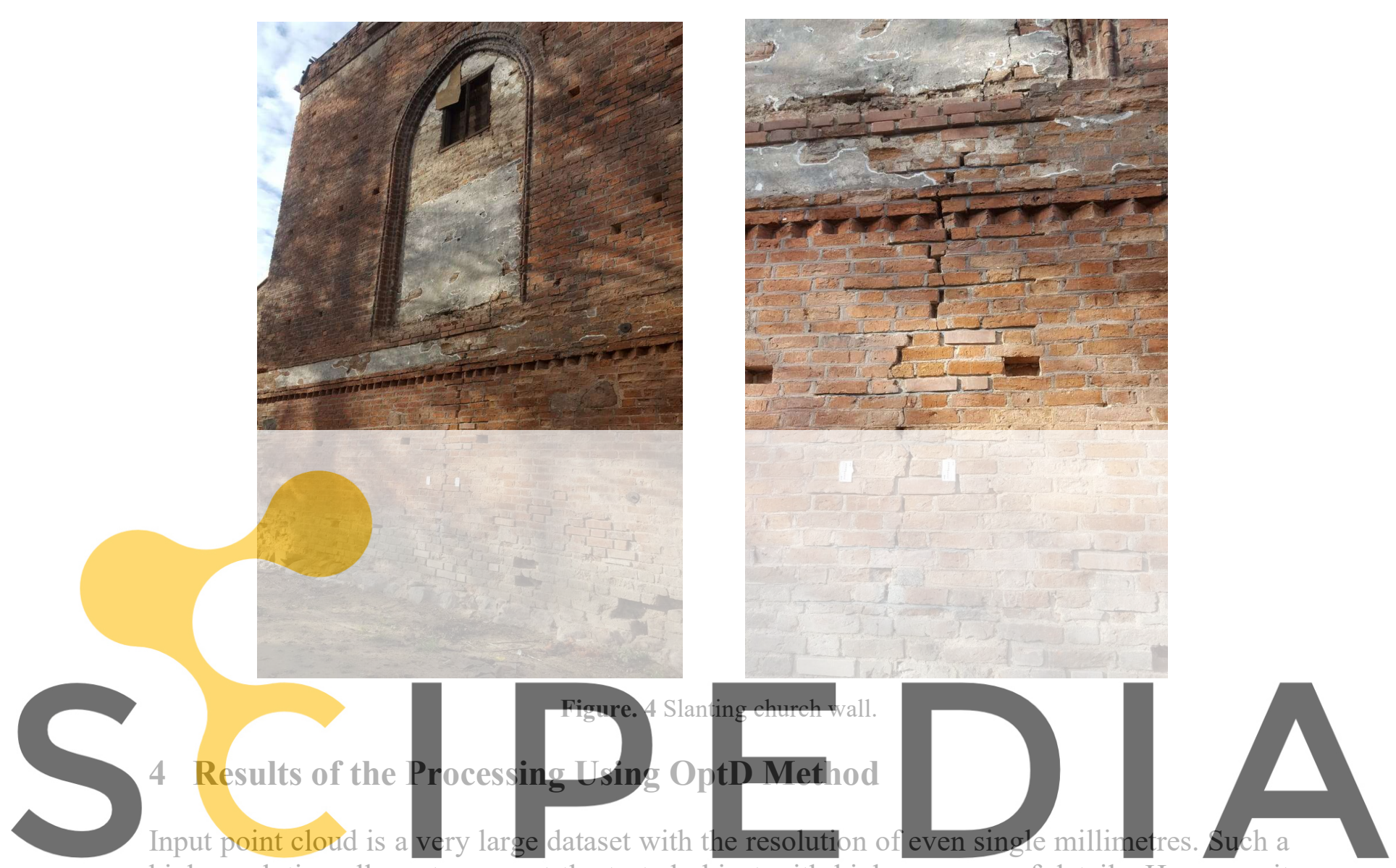

high resolution allows to present the tested object with high accuracy of details. However, it

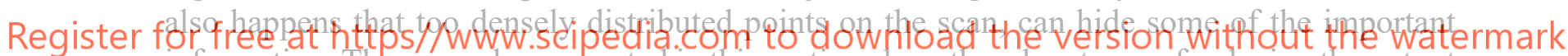
information. The examples presented in this section show the advantages of reducing the output

dataset using the OptD method. As a result of the reduction of the point cloud on selected objects, defects and hazards occurring on them were identified and presented in figures 5, 6 and 7.

Figure 5 shows detection of the basement brick wall defects using the OptD reduction. After the point cloud reduction with the proposed algorithm, those areas that have the greatest effects can be seen more clearly. OptD reduced the most points in areas that did not show significant changes in structure (in the middle of scanned object). In the area where the changes are larger, more points remain. This is visible at the bottom of the scan as a more intense green colour.

Figure 6 presents the second object and the result of the OptD reduction algorithm. The input point cloud (100\%) represents the measured object but it is difficult to observe this fragment of the wall that has been damaged. Reducing the data set by $95 \%$ allows to more accurately observe the area that is characterized by the largest defects in the wall. 
$100 \%$
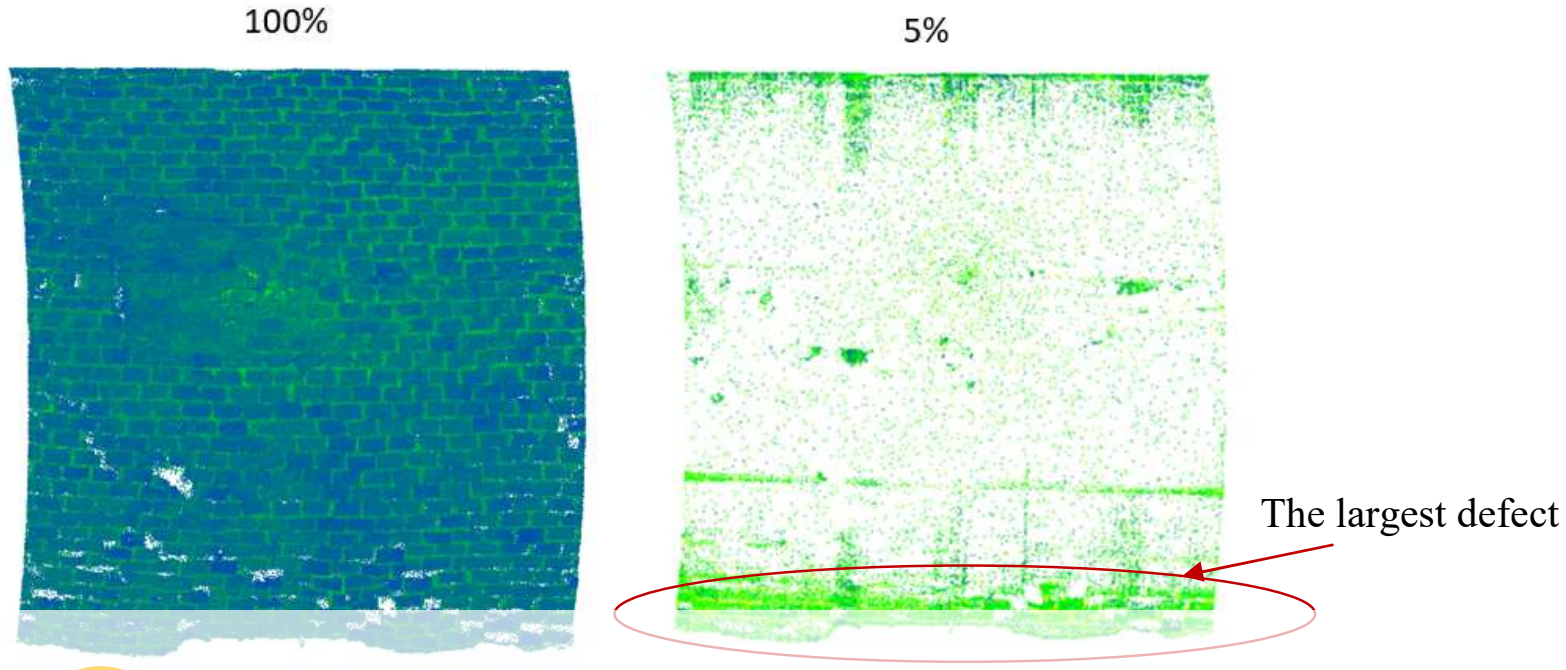
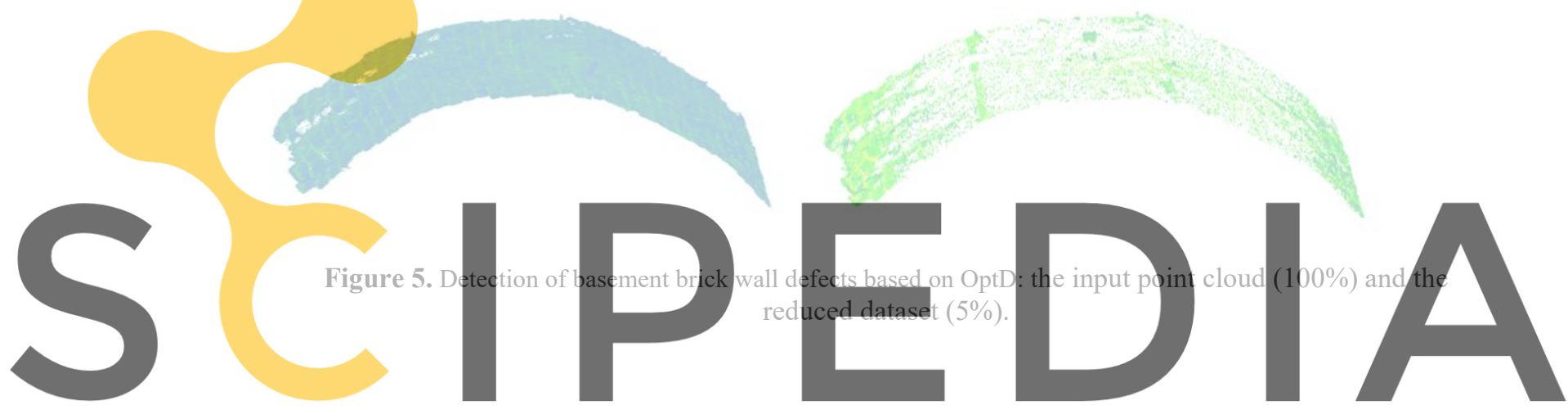

Register for free at https//www.sepipedia.com to download the version without the watermark
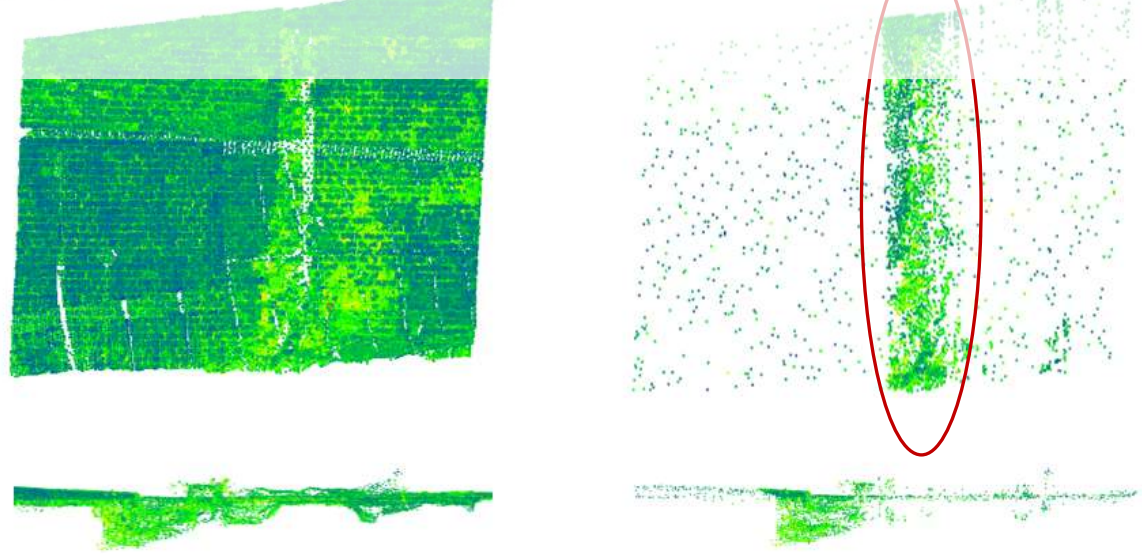

Figure 6. The retaining wall - input dataset and the reduced point cloud. 
The last object is the wall of the church, which as a result of subsidence of the soil leaned out of the vertical and on its surface also formed cracks. Again, the reduction of points allowed to observe (in the form of a darker areas) the place of cracks (red line marked).

$100 \%$
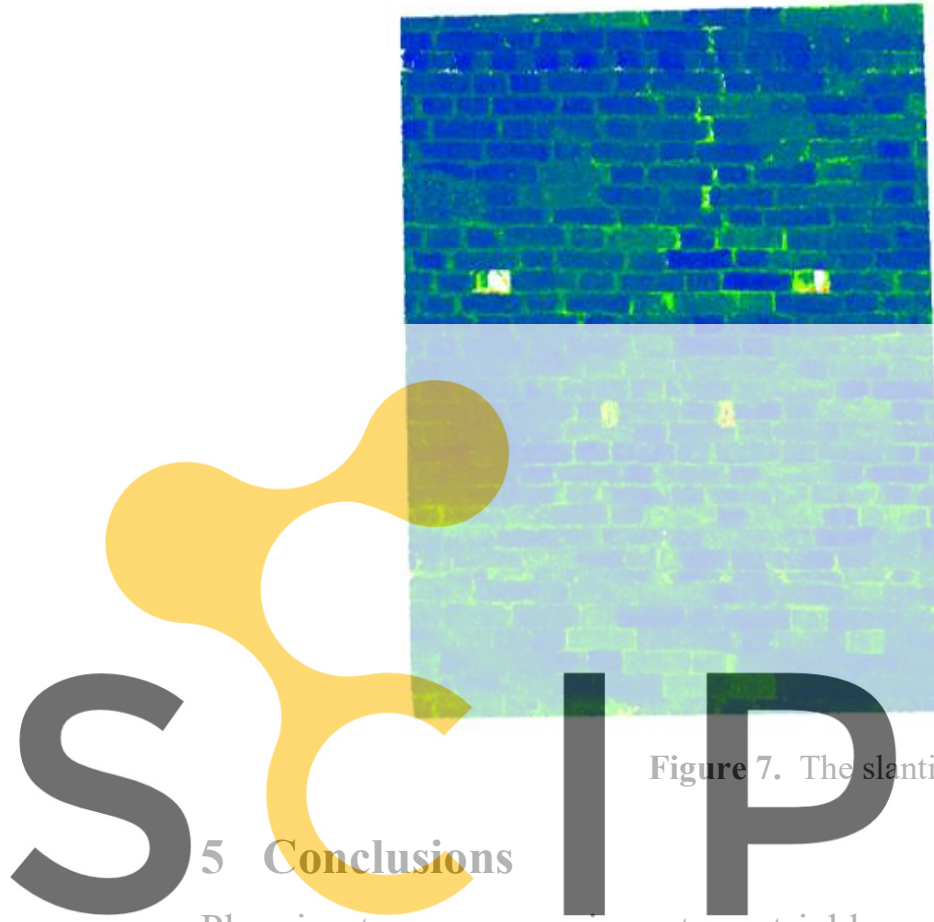

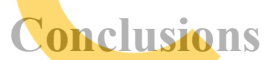 \\ Conclusions}
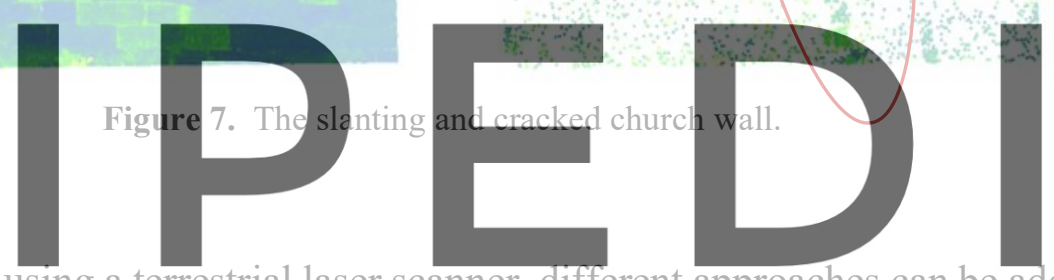

$5 \%$

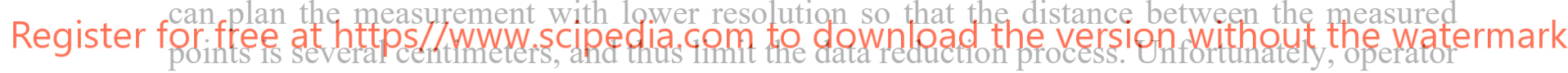

never knows exactly where the laser beam will reflect and which points will be measured and

recorded. This may result in the necessity for re-measurements to udate missing information. One can also take measurements with high resolution but it takes more time, and the big dataset is obtained but a full set of information is available.

A good solution is to use the OptD reduction method in the processing of data obtained from laser scanning. The application of the OptD allows to keep more points of interest area where surface is imperfect (cracks and cavities) and reduce more points of the low interest homogeneous surface (redundant information).

\section{ORCID}

Joanna Janicka: http://orcid.org/ 0000-0002-1504-5354

Wioleta Błaszczak-Bąk: http://orcid.org/ 0000-0001-6169-1579 


\section{References}

Błaszczak-Bąk, W. (2016). New optimum dataset method in LiDAR processing. Acta Geodyn. Geomater. 13, 381388. doi:10.13168/AGG.2016.0020.

Błaszczak-Bąk, W. Koppanyi, Z. and Toth, C. (2018). Reduction Method for Mobile Laser Scanning Data. ISPRS Int. J. Geo-Information. 7, 1-13. doi:10.3390/ijgi7070285.

Błaszczak-Bąk,W., Sobieraj-Żłobińska, A. and Kowalik, M. (2017). The OptD-multi method in LiDAR processing. Meas. Sci. Technol. 28, 7500-7509. doi: 10.1088/1361-6501/aa7444.

Kong, Q., Allen, R., M. Kohler, M. D., Heaton, T. H. and Bunn, J. (2018). Structural health monitoring of buildings using smartphone sensors. Seismological Research Letters vol. 89, (2A), 594-602.

Liang, X. et al.,(2016). Terretrial laser scanning in forest invetories. ISPRS Journal of Photogrametry and Remote Sensing, Vol. 115. doi: 10.1016/j.isprsjprs.2016.01.006.

Matikainen L. (2016). Remote sensing methods for power line corridor surveys. ISPRS Journal of Photogrametry and Remote Sensing, Vol. 115. doi: 10.1016/j.isprsjprs.2016.01.006.

Noel, A. B. Abdaoui, A. Elfouly, T. Ahmed, M. H. Badawy, A. and Shehata, M. S. (2017). Structural health monitoring using wireless sensor networks: A comprehensive survey. IEEE Communications Surveys \& Tutorials vol 19, (3), 1403-1423.

Perez, H., Tah, J.H.M. and Mosavi, A. (2019). Deep Learning for Detecting Building Defects Using Convolutional Neural Networks. Sensors 2019, 19, 3556.

Przyborski M. and Tysiac P. (2018). As-built invenyory of the office building with the use of terrestrial laser scanning. E3S Web of Conferences, Vol 26, doi: 10.1051/e3sconf/20182600011

Suchocki C. and Błaszczak-Bąk W. (2019). Down-Sampling of Point Clouds for the Technical Diagnostics of Buildings and Structures. Geosciences. 1-14. doi:10.3390/geosciences9020070.

Suchocki C., Błaszczak-Bąk W., Damięcka-Suchocka M., Jagoda M. and Masiero A. (2019). An example of using the OptD method to optimization of point clouds in the buildings diagnostics. 4th Jt. Int. Symp. Deform. Monit.
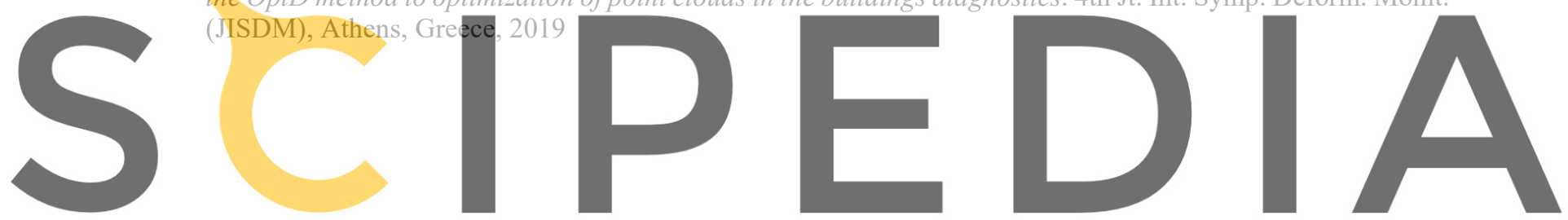

Register for free at https//www.scipedia.com to download the version without the watermark 